\title{
Freud and Jung: The Creation of the Psychoanalytic Universe ${ }^{1}$
}

by David Henderson, Centre for Psychoanalysis, Middlesex University

How can we to think about or imagine the psychoanalytic universe in which we work, think, organise and speak? How can we make sense of a universe of discourse that includes id psychology, object relations, neuropsychoanalysis and existential analysis, and all of the Freudian, Jungian, Kleinian, Lacanian and Kohutian, tendencies and their neo- and post- versions? What sort of historiography will help us to orient ourselves? Is there an approach to the history of psychoanalysis that will serve the interests of historical accuracy and heuristic possiblity?

Nicholas Rand and Maria Torok in their paper, 'The Secret of Psychoanalysis: History Reads Theory,' set out an interesting problem:

... psychoanalysis has been investigated, even challenged, by a variety of other disciplines: biology, linguistics, history, philosophy, literature, and so forth. One may ask whether psychoanalysis can also become its own object, effectively distancing itself from itself. Will historical scrutiny provide criticism from within and thereby alter the nature of psychoanalysis? (Rand and Torok, 1987, p. 278)

\footnotetext{
1 Talk given at The Fragmented World of Psychoanalysis: Is Dialogue Possible?, an international conference organised by the Higher Education Network for Research and Information in Psychoanalysis (THERIP), at the Royal College of Art, London, 26 \& 27 July, 2013
} 
I want to play with this notion and make a couple of suggestions in that direction. These will necessarily be rather bald statements, lacking much supporting evidence or nuance. A string of assertions and non sequiturs.

My point - in a nutshell - is that the best way to account for the history of psychoanalysis, to map psychoanalysis as it exists on the ground today, is to revise the creation myth of psychoanalysis. In 'On the History of the Psychoanalytic Movement,' Freud is unequivocal:

No one need be surprised at the subjective character of the contribution I propose to make here to the history of the psychoanalytic movement, nor need anyone wonder at the part I play in it. For psycho-analysis is my creation... no one can know better than I do what psychoanalysis is. (Freud, 1914, p. 7)

These words express the rage and anguish of the heart-broken lover. They are Freud's response to the end of his affair with Jung. My argument here is that it was the explosive erotic relationship between Freud and Jung that gave birth to psychoanalysis and threw open the imaginative and conceptual space of psychoanalysis as it has actually developed over the past 100 years. All of the substantive theoretical and technical issues that have been taken up and worked on in the history of psychoanalysis were present, either explicitly or implicitly in their relationship. Given the potency of this event it is hardly surprising that they 
were unable to keep it together. The act of conception was more than they could manage as a couple.

In an interview with Kurt Eissler in 1953, Jung reminisced about his first meeting with Freud, when they talked without interruption for 13 hours. He compared their encounter to an act of giving birth. His words are those of a smitten and disappointed lover:

A world happened then... At birth everything is already there! In reality there is no time! Time is nothing! That's what one realizes on such occasions. Those are, there are moments, that are completely timeless... Yes, that was really an intense encounter. What depth he had! God, if only he had only gotten over himself, you know! But there was this neurotic element. If he had gotten over that, yes that - it would have been crazy you know, to ever want anything other than to work with him. (Bair, 2003, p. 117)

We could say that their relationship gave birth to the unrepressed unconscious of psychoanalysis - an unconscious teeming with strange psychic creatures what we call ideas, concepts and intuitions. What was at play in this unrepressed unconscious? Patrick Vandermeersch in his book, Unresolved Questions in the Freud/Jung Debate, focuses on psychosis, sexual identity and religion. (Vandermeersch, 1991) These are big questions, but there is a long list of the issues that were at stake in their dialogue. 
Father

Mother

Libido

Psychic energy

Affect

Transformation

Incest

Dreams

Regression

Fantasy

Symbols

Representation

Death instinct

Negation

Violence

Sacrifice

Teleology

Instinct

Primordial images

Phylogenetic memory

Eros

Language/speech

Number

Complexes/internal objects

Object relations 
Psychosis

Neurosis

Narcissism

Repression

Projection

Mind/body relationship

Religion

Mythology

Transference

Countertransference

The real relationship

Development

Individuation

The social

The collective

Hallucination

Ego

Consciousness

Unconscious

The role of philosophy

Midlife

Technique

Couch/chair

Frequency of sessions

Words/images 


\section{Authority}

\section{Science}

Empiricism

Phenomenology

All these things, which have been and continue to be issues in the extended debate we call psychoanalysis, were at play in their dialogue. The point of performing this litany is to hammer home the fact that Freud's relationship with Jung encompassed far more than his relationships with Breuer, Fleiss, Abraham, Ferenczi, Jones or any of his other collaborators. Between them, Freud and Jung set the agenda for the future evolution of psychoanalysis.

On the $3^{\text {rd }}$ of January, 1913 Freud wrote to Jung: 'I propose that we abandon our personal relations entirely. I shall lose nothing by it, for my only emotional tie with you has long been a thin thread - the lingering effect of past disappoints.'

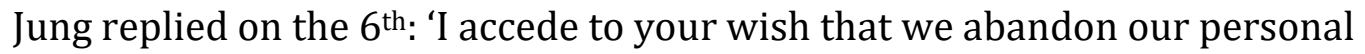
relations, for I never thrust my friendship on anyone. You yourself are the best judge of what this moment means to you. "The rest is silence."' I suggest that these letters mark the creation of the repressed unconscious of psychoanalysis. The dialogue fell into the unconscious. The history of psychoanalysis subsequent to January 1913 can be read a record of symptoms, an archive of the return of the repressed.

Rand and Torok note that the Secret Committee was formed in 1913. They write: 'It follows that in 1913 psychoanalysis itself becomes a secret as it is withdrawn 
- under the seal of absolute secrecy pledged by the members of its most powerful body - into the Committee.' (Rand and Torok, p. 284) For them, Rand and Torok, this is one example, among several that they offer, of what they describe as:

... the basic contradiction that separates psychoanalytic theory from its history: that between the construction of clinical and theoretical tools for the recovery of dynamic repression and the creation of areas of absolute silence, a preservative repression that defies all attempts at discovery. (Rand and Torok, p. 285)

They are describing a conflict between discovery and concealment, truth and power. Or perhaps science and myth? Is psychoanalysis - post-1913 - an uneasy dialectic between science in the service of the patient on one hand and myth in the service of the analyst on the other? Is it a discipline of transparency or a site for fostering a form of religious identity - the identity of the psychoanalyst?

The problem of religion is hotwired into psychoanalysis by the privileging of Freud's self-analysis and Jung's confrontation with the unconscious. These are not scientific events but religious events comparable to Moses on the mountain or Buddha under the bodhi tree. Unless they are studied within the context of comparative religion the prospect of psychoanalytic religious wars seems inevitable. 
By giving the Freud/Jung relationship it proper place (I would say, its historically accurate place) in our history of psychoanalysis we relieve Freud and Jung from the burden of being religious heroes. They are a couple of smart, ambitious guys who fell in love and got in over their heads, and the rest is history.

The way we do the history of psychoanalysis is largely by arguing about the question, 'What is psychoanalysis?' As Freud said, 'No one can know better than I do what psychoanalysis is.' The first session of our MA in psychoanalysis at Middlesex University is entitled, 'What is psychoanalysis?' Robert Langs writes:

Perhaps the most fundamental question we can ask of psychoanalysis is how it is to be defined. What are its essential observables, methods, axioms and postulates? And where is its center - the few sine qua nons that define its most basic features? (Langs, 1993, p. 555)

For me this is not a very interesting or useful question. I would rather ask, 'Where is psychoanalysis?' In terms of what I am arguing today - psychoanalysis is between Freud and Jung. As Freud himself remarked, it is between medicine and philosophy. We might add, that it is between science and myth. Between past and future. Between conscious and unconscious. Between the primordial and the present. Between silence and speech. Between self and other. Between personal and impersonal. Between ego and superego. Between individual and collective. Between mommy and daddy. Between 3 p.m. and 3:50 p.m. My advice would be, if you want to know what psychoanalysis is go into those gaps and see what crazy, amazing and heart-breaking things people are up to. But good luck trying 
to define it! If pressed, I would define psychoanalysis is a disciplined journey into the between.

Does this statement: psychoanalysis is a disciplined journey into the between really mean anything? I think so. The between is everywhere so that is easy enough. The tricky bit is disciplined journey. What is the discipline? The discipline I am interested in is the discipline exercised by the analyst or therapist. What is the intellectual, affective, psychological and behaviouraI profile of the working analyst? I think that this could be an extremely fruitful area for dialogue, debate and controversy. Freud advocates free association and evenly hovering attention. Jung states that when listening to a dream he reminds himself that he has no idea of its meaning. Bion advises us to approach the session without memory or desire.

It seems to me that what all of these rules of thumb have in common is a type of epistemology. They are not advocating a dream-like reverie or a trance state but a radical attitude of unknowing on the part of the analyst. A principled foreswearing of knowledge. An analyst who really, really does not know has a huge amount to offer.

Leon Ginsberg observed that:

In spite of its tremendous impact on mankind, paradoxically enough, it has not yet been possible to place and classify psychoanalysis within any of the existing fields of knowledge. (Ginsberg, 1969, p.517) 
Well good. Perhaps psychoanalysis is not a type of knowledge, but a type of ignorance. Perhaps it is precisely the disciplined, learned ignorance of the analyst that makes life possible for the patient.

\section{References}

Bair, Deirdre (2003), Jung: A Biography, London: Little Brown

Freud, Sigmund (1914), 'On the History of the Psycho-Analytic Movement,' SE14

Ginsberg, Leon (1969), 'New Ideas: Conflict and Evolution,' The International Journal of Psychoanalysis, 50

Langs, Robert (1993), 'Psychoanalysis: Narrative Myth or Narrative Science,' Contemporary Psychoanalysis, 29

Rand, Nicholas and Maria Torok (1987), 'The Secret of Psychoanalysis: History Reads Theory,' Critical Inquiry, 13 (Winter 1987)

Vandermeersch, Patrick (1991), Unresolved Questions in the Freud-Jung Debate: On Psychosis, Sexual Identity and Religion, Leuven: Leuven University Press 